\title{
The Role of Structure Novelty on the Efficacy of Recasts: An Experimental Study on Iranian Upper-intermediate EFL students
}

\author{
Mohammad Reza Najafi \\ Department of Foreign Languages, Shahid Bahonar University, Kerman, Iran \\ Zoobinshid Arshad \\ Department of Foreign Languages, Islamic Azad University, Shiraz, Iran
}

\begin{abstract}
-recent developments regarding error correction demonstrate an increasing interest in finding the determining elements that are influential in the effectiveness of recasts. In line with this trend, present paper aims at investigating the effect of structure novelty on the effectiveness of two types of recasts, namely combination recast and single-move recast. To this end, 60 upper-intermediate students in 4 classes were chosen to form 2 experimental groups (each 2 classes formed 1 experimental group), and later the two abovementioned corrective feedback were utilized by the teacher in each experimental group to correct the erroneous utterances stemming from both newly and previously learned structures. To collect the required data students participated in 10-minute discussion for 10 sessions. Then two paired t-tests were administered after the treatment to compare the performance of both groups on the post-test. The results indicated that structure novelty is a determining factor regarding the effectiveness of the recasts owing to two reasons. Firstly, while both types of recasts acted the same on correcting the incorrect structures rooted in the previouslylearned structures, combination recasts were more effective over single-move recasts in correcting the fallacious structures emanated from newly-learned structures. Secondly, upper intermediate students whom are believed to benefit from recasts (Ammar and Spada, 2006; Philip, 2003) due to their high proficiency couldn't make the most of recasts as their erroneous utterances stemmed from their novel and newly-learned structures.
\end{abstract}

Index Terms - structure novelty, combination recast, single-move recast, uptake

\section{INTRODUCTION}

Multitude lines of research (Allwright \& Bailey, 1991; Wells, 1996; Lyster \& Ranta 1997; Mackey, Gass \& McDonough, 2000; Sheen, 2004; Barkhuizen \& Ellis, 2005; Sheen, 2006; Lyster \& Mori, 2006), scrutinizing the classroom interactions, unveil that scientists of this field have been hard at work probing deep into the classroom interaction to figure out the intricacies of interactions taking place between the teachers and the learners. The findings reveal that a classroom interaction embodies three moves, namely Commence, Response, and Feedback. The feedback moves, referring to all the moves following a student's response, fall into two categories, according to Long (1996), positive feedback and negative feedback. Negative feedback, manifesting the lack of preciseness in the learners' utterances in terms of the structures and content (Ellis, 2009), are the central tenets of this paper.

Since the advent of Swain's (1985) output hypothesis, the role of negative feedback as a strategy to make the students aware of their deviant utterances has come into vogue. The basis of her initial claim was due to her research on French immersion students. She argued, despite of the fact that the students were exposed to 6 or 7 years of comprehensible input, they weren't able to conduct an impeccable exchange of ideas, exchanges without grammatical and syntactic deviation. Swain (2000) asserted the critical role of output in language learning in view of the fact that output causes learners to process the language profoundly. Swain (2000, p.99) contended "Output may stimulate learners to move from the semantic, open-ended, strategic processing prevalent in comprehension to the complete grammatical processing needed for accurate production." Promoting "noticing" as one of the functions of output is of the paramount importance since learners could be notified that they don't know how to get the massage, as it's meant, across precisely; moreover, they could notice the gaps in their interlanguage. Having said that, it is inferred that negative feedback make the learners notice the gap between what "is just said" and what "should have been said", that is, the act of noticing the gap between interlanguage forms and target forms.

In 2000, Merrill Swain published an article under the rubric "The output hypothesis and beyond: Mediating acquisition through collaborative dialogue. In this paper she was convinced by Kramsch (1995a) and van Lier (2000) that the 'terms 'input' and 'output' have lost their credence due to inhibiting effect of the 'conduit metaphor' on the development of a broader understanding of second language learning." Being under the influence of Vygotsky's sociocultural theory, proposing that cognitive functions such as learning are mediated by semiotic tools, namely 
language, and in co-operation with other people, Swain aped to stop using the terms mentioned above and replaced them with the term 'collaborative dialogue'. In her article, Swain (2000) argued that the term output should be broadened to embrace its function as a socially- constructed cognitive tool.

The importance of corrective feedback, as one type of negative feedback could be recognized by Vygotsky's ZPD framework and also Wells' (2000) claim. Regarding ZPD framework, Vygotsky defined it as "the distance between the actual developmental level as determined by independent problem solving and the level of potential development as determined through problem solving under the adult guidance or in collaboration with more capable peers" (Johnson, 2004, p.109). Once applying the notion of ZPD to language learning, it will be perceptible that the potential level of development, beyond a shadow of a doubt is the zone of proximal development; therefore, according to Vygotsky "an essential feature of learning is that it creates the zone of proximal development"; that is, the pedagogical environment that the students are provided with can awaken a variety of learning processes. Undoubtedly, on the condition that the learner is interacting with the teacher and the peers, the learning processes start to function (Johnson, 2004). On that account, it's concluded that corrective feedback as powerful means can empower teachers to regulate the process of turning potential levels of learning to actual ones.

Wells (2000) argues that "one of the characteristics of utterance, whether spoken or written, is that it can be looked at simultaneously as process and product: as "saying" and as "what is said". In "saying" learners are involved in a cognitive activity to make "what is said"; in other words the outcome of that activity. Therefore, while the outcome is being made, corrective feedback, as reactive pedagogical strategies, could help learners notice their erroneous utterances; moreover, construct new non-deviated language knowledge.

Lyster \& Ranta could be considered as the pioneers in this field. They have made a substantial contribution to this field by broadening the teacher's horizons over the existing ways to correct students' erroneous utterances. They managed to categorize feedback into six types: explicit correction, recast, clarification request, metalinguistic clues, elicitation and repetition, after observing and documenting immersion classroom interactions.

The effectiveness of each corrective strategy, particularly recasts, has been examined through many lines of research; however, there has been glaring inconsistencies in their findings. For instance, researchers such as Lyster \& Ranta (1997), Lyster (1998), and Panova \& Lyster (2002) concluded that "those students who received recasts did not demonstrate subsequent gains in their L2 accuracy. Nevertheless, other research studies (Ayoun, 2001; Braidi, 2002; Doughty \& Varela, 1998; Han, 2002; Havranek, 2002; Iwashita, 2003; Leeman, 2003; Mackey \& Philip, 1998; Oliver \& Mackey, 2003) found the opposite findings that recasting increases learners' noticing and the development of morphosyntactic features.

Presently, the issue of the efficacy of recasts should be scrutinized through a new perspective as innumerous research studies with inconsistent findings exist. In fact, this issue needs a new outlook. Therefore, Sheen (2006) by classifying recasts into single-move and multi-move altered the researcher's point of attention from focusing on a mere recast to the facilitative factors, features of recasts, which affect their saliency. Sheen (2006) considered several features for each category which can affect the efficacy of recasts, and also make a unique type of recast. Given the saliency of recasts as an influential factor in making the learners notice the corrective purpose of the feedback, another little-studied issue which is worth investigating in terms of discovering influential elements in effectiveness of recasts is structure novelty, defined as newness of structure. In fact, this study intends to find out if the efficacy of recasts is influenced by the newness of structure which students produce incorrectly. To this end, combination recasts and single-move recasts were employed to correct the erroneous use of causative 'get' and 'have' in the utterances of the students in their current level as a new grammar point and erroneous use of simple past and present perfect as their previously-learned grammar. Therefore, the present study finds this an area worthy of investigation and specifically addresses the following research questions:

1. Do single-move and combination recasts have differing effects in correcting erroneous grammatical patterns stemming from students' newly-learned structures?

2. Do single-move and combination recasts have differing effects in correcting erroneous grammatical patterns stemming from students' previously-learned structures?

\section{LITERATURE REVIEW}

A methodical study over the literature review of language learning and teaching indicates that effects of various corrective feedback has long been of central importance to foreign and second language teachers in a variety of contexts; additionally, The efficacy of each has been studied through numerous research studies. Due to the frequent occurrence of recasts in L2 classrooms, an increasing attention from researchers has been paid to this corrective feedback in recent years. Nevertheless, the discrepancies among the findings of the studies in this field have turned this issue into one of the hotly debated arguments in second language learning. To show the dominance of recasts, these studies were conducted. Doughty (1994) reported recasts comprised 70\% of the teachers' corrective moves. Some years later, Lyster \& Ranta (1997), observing immersion classes, reported 55\%. Panova \& Lyster (2002) in their study recorded 55\%, and Lochtman (2002) found out recasts as the most recurrent feedback (30.5\%). In Nishita' (2004) research recasts made up $60 \%$ of the corrective moves. Lyster \& Mori (2006) conducted a research in two different instructional settings French and Japanese immersion in search of the effects of explicit correction, recasts, and prompts on learner uptake 
and repair. The results indicated high frequency of recasts, 54\% in French immersion and 65\% in Japanese immersion. Therefore, it is indisputable from these results that recasts hold a special place in teachers' tool belt of corrective feedback techniques. The reason why recasts are the most chosen is related to their implicit nature, which maintains the flow of interaction between the teacher and the student, while other strategies namely elicitation, clarification requests, and repetition, might interrupt the meaningful interaction.

\section{A. On the Efficacy of Recasts}

Proved as the most frequently employed corrective feedback from teachers, recasts were examined by many researchers to figure out if they are the most effective corrective moves too. The first observational study conducted to investigate the efficacy of recasts was carried out by Lyster \& Ranta in 1997 in an immersion context. The obtained findings proved a clear inclination from teachers to employ the implicit form of corrective feedback, namely recasts and translation, 55\% and 22\% respectively. Although Lyster and Ranta (1997) found recasts as the most dominant corrective move, they were followed by a low rate of uptake from the students. Surprisingly enough, they found that the highest rate of uptake belonged to the least employed corrective feedback, i.e. metalinguistic feedback, clarification request, and elicitation.

Similarly, an observational study by Panova and Lyster (2002) on an early-intermediate adult ESL classroom in Quebec substantiated the findings of Lyster \& Ranta (1997). Their study indicated that recasts were the most recurrent type of corrective feedback (55\%). Nonetheless, recasts were followed by low uptake and repairs rates, $40 \%$ and $13 \%$ respectively. The findings of this study were twofold. Firstly, early-intermediate students had difficulty recognizing that they were being corrected by recasts as they didn't perceive recasts as corrective in nature. Secondly, recasts "may not be the most effective way of promoting negative evidence" (p. 591).

Another experimental study in this regard was carried out by Lochtman (2002). He conducted this study in high school setting, L2 German classrooms in Belgium, on the efficacy of recasts. The results indicated that $90 \%$ of erroneous structures received corrective feedback out of which recasts and elicitations comprised the most proportion of the corrective moves, $30.5 \%$ and $30.2 \%$ respectively; however, they found that recasts resulted in the least percent of uptake (47.5\%). Lochtman's findings were in line with that of Lyster \& Ranta (1997) and Panova and Lyster (2002). Hence, it is concluded that all above-mentioned studies unanimously voted for the inefficiency of recasts in making the students aware of their erroneous utterances.

\section{B. A Turning Point}

Disappointing findings of both experimental and observational studies (Lyster and Ranta, 1997; Panova and Lyster, 2002; Lochtman, 2002) in proving recasts as an effective form of corrective feedback, to a large extent, shifted the focus of the studies to identifying pivotal factors influential in the efficiency of recasts. Below, a number of studies trying to investigate the intervening factors in efficacy of recasts are presented.

Lyster (1998) conducted a study in an attempt to analyze features of student-teacher interaction that may influence the potentiality of recasts to be noticed as negative evidence. He recorded 18 hours of interactions during 27 lessons in 4 immersion classrooms at the primary level. 377 recasts were categorized according to their pragmatic functions. According to Lyster, "recasts and non-corrective repetition fulfill identical, meaning the students had difficulty distinguishing recasts as corrective moves or confirmation checks."

Philip(2003) examined the role of proficiency level of the students as an intervening factor in the efficacy of recasts, along with the features of length and number of changes in learners' noticing of recasts. To fulfill his intentions in the study, Philip chose 18 female and 15 male students. The students participated in five NS-NNS dyadic interaction sessions; besides, they attended test sessions in which they performed two tasks. During performing tests the participants were shown a certain number of pictures to derive questions from. Recasts were employed in response to the erroneous utterances of the students. Recall was used to measure how well the participants could remember the recasts to measure the students noticing recasts. The ability of intermediate and high-intermediate groups in recalling the $70 \%$ of the provided recasts in comparison with that of low intermediate learners which rated $60 \%$, proved the significant relationship between the proficiency level of the learners and the recasts recall. Another important finding of this study was the shortness of the employed recasts, in fact, this facilitative feature made it easy for the students to notice the corrective nature of recasts.

Sheen (2004) conducted a study across international settings (French Immersion, Canada ESL, New Zealand ESL and Korean EFL) to enquire into the momentousness of the saliency of recast as a significant factor intensifying its effectiveness. The results were twofold. Firstly, it was made clear that recasts made up the highest proportion of corrective feedback in the Korean EFL and New Zealand ESL (83\% and 68\%, respectively), and in Canadian Immersion and ESL classrooms 55\% (for both), that's to say, recast was the most recurrent feedback type. Secondly, it was proved that to a large extent the effectiveness of recasts was related to how salient they were, and how far linguistic form was the focal center of attention.

Ellis, Loewen and Erlam (2006) studied the factor of "saliency" as an influential and determining element by comparing the effect of implicit corrective feedback (recasts) and explicit feedback (metalinguistic) on deviated linguistic forms of students' utterances. In this study, low intermediate learners as participants of the study made up two groups in which they were assigned to perform two tasks. The participants during performing their tasks received 
corrective feedback in the form of recasts and metalinguistic information. The results of the study indicated the superiority of explicit corrective strategies over the implicit ones since the former "seems more likely to promote cognitive comparison and aids learning" (p. 364).

To find the determining characteristics that improve the effectiveness of recasts, Loewen and Philip (2006) conducted a study on L2 adult English second language learners. In this study there were, according to the researchers, 12 teachers and 118 learners. The students' erroneous utterances through 17 hours of meaning based interaction were corrected with 3 different types of corrective feedback, namely recasts, elicitation, and metalinguistic moves. The initial results proved that " recasts were beneficial at least $50 \%$ of the time". The employed recasts in this study could be distinguished by determining characteristics which made a new type of recast with a new corrective purpose. By and large, this study proved that the confusion which was made by recasts due to their not being clear and understandable for the students can be minimized by "phrases, prosodic and discoursal cues that teachers provided" (Leown and Philip 2006).

A quasi-experimental study was conducted by Ammar and Spada in 2006. This study aimed to investigate the effectiveness of recasts and prompts. To reach the intended goal 64 sixth grade students in the Montreal area were chosen. The students made up 2 experimental and one control groups. The students in experimental groups were provided with recasts and prompts in case of producing incorrect form of third-person possessive determiner "his" and "her". Once the 4- week treatment was over. The participants' knowledge of aimed structure was assessed. The results indicated that all students participated in the study benefited from the provided corrective moves; however, the study substantiated that the students enjoyed the benefits of prompts more than that of recasts; moreover, it was proved that "high- proficiency learners benefited equally from both prompts and recasts, whereas low-proficiency learners benefited significantly more from prompts" (Ammar \& Spada 2006).

Ammar in 2008 conducted a quasi-experimental study examining the effect of recasts in comparison with prompts on the erroneous utterances of learners learning English $3^{\text {rd }}$ person on possessive determiners. To reach the specified goals, the researcher chose 64 students to form 3 classes; erroneous utterances were corrected by prompts and recasts. To exam the effect of provided corrective feedback, the participants were assigned to do an oral picture description task and computerized fill-in the blank tasks. Results indicated that prompts were more effective particularly for low-level learners.

By taking into consideration all the obtained findings of both observational and experimental studies, it is concluded that the significant criticism leveled against recasts was due to their being ambiguous to the students as they were taken as "confirmation checks" and it was as a result of, as Truscott $(1996 ; 1999)$ quite rightly noted, "insaliency of recasts", which made it fathomless for the students to notice whether they were being corrected. However, one of the most significant findings emerging from the above-mentioned studies (Lyster 1998; Philip 2003; Sheen 2004; Elis et al, 2006; Loewen and Philip 2006; Ammar and spade 2006; Ammar 2008) is that saliency and also high proficiency of students are of the paramount importance in intensifying the effectiveness of recasts, that is, the more salient recasts are and the higher students in proficiency the more effective the recasts will become.

Sheen (2006) through a seminal study discovered a number of characteristics which can contribute to the efficacy of recasts. She came up with a coding system in which recasts were classified under two categories, single-move and multi-move. She managed to define them as follow:

Multi-move recasts: entail more than one teacher feedback move containing at least a single recast in a single teacher turn. They included three different types of recasts, namely corrective, repeated, and combination.

Combination recast conjoined with metalinguistic information on the one hand and single move recasts on the other hand are the main focus of the present study which are defined and illustrated in the following.

Combination recast: recasts that occur with other corrective feedback types, e.g. metalinguistic information.

Example 1:

S: I haven't done my home work yesterday.

T: I didn't do my homework yesterday. Definite time in the past!

Single-move recasts: entail only one recast move in a single teacher turn.

Example 2:

S: I had my brother to fix my car.

T: I had my brother fix my car.

\section{Uptake}

In quest of finding the effectiveness of corrective feedback on language acquisition, Researchers have utilized four major direct or indirect measures, namely (a) uptake and learner repair (b) immediate post-tests (c) delayed post-tests (d) learner perception noticing of $C F$ by means of stimulated recall. The present study took advantage of "uptake and learner repair" and " immediate post-tests. Following Lyster \& Ranta (1997), uptake is defined as "any student responses (learner output) immediately following a teacher corrective feedback". Uptake is classified in the following categories repair and needs repair. Repair involves 'successful uptake' a benchmark indicating the efficacy of corrective feedback. Needs repair refers to uptake that is still in need of correction. Learner's acknowledgements such as 'yes', 'yeah', or 'right' were coded as needs repair, since the learner did not correct the erroneous statement. 
As the issue of recasts' being effective has grown in importance in light of recent studies, more determining factors contributing to the efficacy of recasts need to be discovered. Accordingly, this paper seeks to investigate the effect of the novelty of the grammar point on the efficacy of two types of recasts. To accomplish the aims of the present study, combination recasts combined with metalinguistic information and single-move recasts were selected to see the effect of each one on reducing the likelihood of the upper-intermediate learners' incorrect use of the grammatical points (causative 'get and 'have') which were to be learned in comparison with those grammatical points (present perfect and simple past) which were taught in previous terms and were part of the students' old knowledge.

\section{SAMPLING}

To fulfil the objectives of this study, 60 male and female upper-intermediate English learners were chosen. The classes consisted of 15 students and they were held in Navid English Institute, Shiraz, Iran. The participants, who were selected through cluster sampling, formed 2 experimental groups. That's to say, for each experimental group 2 classes were allocated. Besides, in each experimental group only one of the target corrective moves was employed. Touchstone 4B (Cambridge University press) was chosen as the means of instruction. The participants, ranging in age from 20 to 30 , met two sessions a week (each session was held for 2 hours). The researchers were in charge of the classes.

\section{MATERIALS}

\section{A. Oxford Placement Test}

To assure the researchers that all the participants of this study shared a similar command of English language, Oxford Placement Test was administered at the beginning of the term.

\section{B. Cambridge Test Booklet}

To ensure the reliability and validity of post-test a 40-item proficiency test from Cambridge test booklet, developed by Cambridge University, was selected in order to measure participants' level of proficiency after the administration of the treatment.

\section{A Sound Recorder}

To have a record of the events of the class for further analysis, a recorder was used by the observer.

\section{A Fill-in Chart}

To chart the number of corrective moves produced by the teacher, and also the students' uptake, the observer utilized a fill-in chart.

\section{Data Collection}

All sessions were initiated by discussions on the topics presented in the book (each unit includes one main topic and 4 subtopics). The participants had passed 7 levels and had been familiar with simple past and present perfect; therefore, the grammar points were parts of their old knowledge; however, 'Causative Structures' was the first grammar box of the beginning unit of their current term. To collect the required data, from the third session the students in each experimental group, combination recast group and single-move recast group, were assigned to take part in the discussions run by the teacher every session. To make sure the students would use the target grammar points, they were written on the board at the beginning of each session. During the discussions, incorrect forms of the intended grammar points in each experimental group were corrected with respective corrective feedback. For the duration of 10 sessions the two researchers, one as a teacher and the other as an observer to record events of the class, were present in the class. The observer recorded the discourse occurring among the students and between the teacher and the students as the required data.

\section{Data AnAlysis Procedure}

The collected data was statistically analyzed by SPSS. Firstly, a t.test was run to compare the results of pre-test for the two groups in order to ensure the homogeneity of the experimental groups. Later, the number of corrective moves provided by the teacher and recorded by the observer, in the course of the discussions during the 10 session in both experimental groups, were analyzed by two Pearson chi-square analyses. Finally, two paired t.tests was conducted on the obtained data from post-test to compare the attained means of the two experimental groups regarding the old and new grammar.

\section{DATA ANALYSIS AND RESUlt}

The gathered data through the discussions and the post-tests were utilized to answer the research questions enquired into by the present study. Table 1 compares the results obtained from the participants' performance on the pretest. The 
pretest was administered prior to the treatment with the purpose for the researchers to be assured of the participants' homogeneity.

TABLE 1:

A T.TEST COMPARING THE PARTICIPANTS OF THE EXPERIMENTAL GROUPS ON PRE-TEST

\begin{tabular}{|l|l|l|l|l|}
\hline Group & N & Mean & SD & SEM \\
\hline Combination recast & 30 & 86.33 & 4.79 & 0.88 \\
\hline Single-move recast & 30 & 84.93 & 4.44 & 0.82 \\
\hline
\end{tabular}

It can be seen from the presented data that the students in the experimental group 1 (combination recast) performed slightly better; nevertheless, the presented mean score proves that there is no significant differences among the participants of the two experimental groups. Hence the homogeneity of the subjects is beyond question.

\section{A. Comparing the Number of Provided Corrective Feedback}

Regarding the effect of structure novelty on the efficacy of combination and single-move recasts, first, the correction of the students' deviated utterances of each experimental group was carried out by each one of the two above-mentioned recasts, then two Pearson chi-square tests, were conducted on the charted corrective moves to reach two goals. Firstly, to find out if there is a significant difference between the employed corrective moves. Secondly, to figure out the number of corrective feedback produced during the 10 sessions.

The number of combination and single-move recasts produced by the teacher in response to the erroneous utterances which were originated in the students' newly-learned structures, is presented in Table 2.

TABLE 2:

THE NUMBER OF CORRECTIVE FEEDBACK PRODUCED REGARDING NEW GRAMMAR

\begin{tabular}{|l|l|l|l|l|}
\multicolumn{5}{c}{ THE NUMBER OF CORRECTIVE FEEDBACK PRODUCED REGARDING NEW GRAMMAR } \\
\cline { 3 - 4 } & & Experimental groups & Uptake & Total \\
\cline { 3 - 4 } & & Repaired & Needs-repair & \\
\hline \multirow{2}{*}{$\begin{array}{l}\text { New } \\
\text { Grammar }\end{array}$} & Combination recast & 85 & 35 & 120 \\
\cline { 2 - 4 } & Single-move recast & 37 & 78 & 115 \\
\hline & Total & 122 & 113 & 235 \\
\hline
\end{tabular}

As Table 2 illustrates, during 10 sessions, 235 corrective moves, out of which combination and single move recasts consisted of 120 and 115, respectively, were produced. By referring to uptake column to find out how the students reacted to corrective feedback, we can understand combination recast feedbacks led to repair in 85 corrective treatments, that's to say, more than $70 \%$ of the error treatments led to repair; besides, in 35 times it led to needs-repair, that is, students used acknowledgment uptake which is producing words or phrases like "yes, yes" or "right", this kind of uptake uncovers that students sensed that they had made mistakes. In the following, Table 3 gives a statistical analysis of the data presented in table 2 .

TABLE 3:

CHI-SQUARE TEST COMPARING CORRECTIVE FEEDBACK PRODUCED REGARDING NEW GRAMMAR

\begin{tabular}{|l|l|l|l|}
\hline & Value & df & Asymp. Sig. (2-sided) \\
\hline Pearson Chi-Square & $35,158(\mathrm{~b})$ & 1 &, 000 \\
Continuity Correction(a) & 33,626 & 1 &, 000 \\
Likelihood Ratio & 36,082 & 1 &, 000 \\
Linear-by-Linear Association & 35,008 & 1 &, 000 \\
N of Valid Cases & 235 & & \\
\hline
\end{tabular}

Due to the fact that significance level of Pearson Chi-square is less than .05, it is concluded that there is a significant difference between the corrective feedback moves. This uncovers that students had different levels of uptake to corrective moves.

The number of combination and single-move recasts produced by the teacher in response to the erroneous utterances which were originated in the students' previously-learned structures, is presented in Table 4.

TABLE 4:

THE NUMBER OF CORRECTIVE FEEDBACK PRODUCED REGARDING OLD GRAMMAR

\begin{tabular}{|l|c|l|l|l|}
\hline & & Uptake & \multirow{2}{*}{ Total } \\
\cline { 2 - 5 } & Experimental groups & Repaired & Needs-repair & Tot \\
\cline { 2 - 5 } Old Grammar & Combination recast & 76 & 25 & 101 \\
\cline { 2 - 5 } & Single-move recast & 69 & 33 & 102 \\
\hline Total & 145 & 58 & 203 \\
\hline
\end{tabular}

Table 4 highlights the existing similarity between the experimental groups in terms of their uptake from the two aimed corrective feedback. In fact, nearly as many erroneous utterances in combination recast group as in single move recast group led to repair; moreover, it can be held true for the number of incorrect utterances which led to needs-repair in both groups. However, to see if the data is statistically significant the chi-square test was run on the data, the result of which is presented in table 5 . 
TABLE 5:

CHI-SQUARE TEST COMPARING CORRECTIVE FEEDBACK PRODUCED REGARDING OLD GRAMMAR

\begin{tabular}{|l|l|l|l|}
\hline & Value & df & Asymp. Sig. (2-sided) \\
\hline Pearson Chi-Square & $1,436(\mathrm{~b})$ & 1 &, 231 \\
Continuity Correction(a) & 1,088 & 1 &, 297 \\
Likelihood Ratio & 1,440 & 1 &, 230 \\
Linear-by-Linear Association & 1,429 & 1 &, 232 \\
N of Valid Cases & 203 & & \\
\hline
\end{tabular}

It is apparent from this table that there is no clear significant difference between the combination and single-move recasts in correcting the students' deviated structures because the significance level is more than $.05(>.05)$.

\section{B. Comparison of the Post-tests}

To recognize whether the intended corrective feedback were effective on reducing the likely production of incorrect grammatical structures stemming from the new and old knowledge, two paired t-tests were conducted. The results are shown in Table 6 and 7.

TABLE 6:

A T TEST COMPARING THE EXPERIMENTAL GROUPS ON POST-TEST REGARDING NEW GRAMMAR

\begin{tabular}{|l|l|l|l|l|l|l|l|}
\hline & $\begin{array}{l}\text { Experimental } \\
\text { groups }\end{array}$ & mean & $\begin{array}{l}\text { Std. } \\
\text { Deviation }\end{array}$ & $\begin{array}{l}\text { Std. Error } \\
\text { Mean }\end{array}$ & t & df & Sig.(2-tailed) \\
\hline $\begin{array}{l}\text { New } \\
\text { Grammar }\end{array}$ & $\begin{array}{l}\text { Combination-recast } \\
\text { Single-move recast }\end{array}$ & 2.83 & 3.86 & .704 & 4.02 & 29 & .000 \\
\hline
\end{tabular}

As it is evident from Table 6 , the significance value of the scores is .000 which is less than .05 , and it shows that the difference between the means of the two groups regarding the old grammar is statistically significant.

TABLE 7:

\begin{tabular}{|c|c|c|c|c|c|c|c|}
\hline & $\begin{array}{l}\text { Experimental } \\
\text { groups }\end{array}$ & mean & $\begin{array}{l}\text { Std. } \\
\text { Deviation }\end{array}$ & $\begin{array}{l}\text { Std. Error } \\
\text { Mean }\end{array}$ & $\mathrm{t}$ & df & Sig.(2-tailed) \\
\hline $\begin{array}{l}\text { Old } \\
\text { Grammar }\end{array}$ & $\begin{array}{l}\text { Combination-recast } \\
\text { Single-move recast }\end{array}$ & .83 & 2.74 & .50 & 1.66 & 29 & .107 \\
\hline
\end{tabular}

As the significance value is higher than .05 it can be concluded that the difference is not statistically significant.in fact, the students of both experimental groups made the most of both the combination and single move recasts.

\section{DISCUSSION}

This study investigated the potential role of structure novelty on the efficacy of combination recasts and single-move recasts. To effectuate the intentions of the present study two questions were presented. In the following, based on the findings, the study tends to answer the questions.

1. Do single-move and combination recasts have differing effects in correcting erroneous grammatical patterns stemming from students' newly-learned structures?

2. Do single-move and combination recasts have differing effects in correcting erroneous grammatical patterns stemming from students' previously-learned structures?

On the first research question, according to Table 2, showing what percent of recasts manage to repair the erroneous structures stemming from new knowledge and Table 3 presenting the obtained results from the first chi-square test, we arrive at a conclusion that combination and single-move recasts have differing effects in correcting the students' deviated structures concerning their levels of uptake; furthermore, from the mean score appearing in Table 6 through the t-test analysis which indicates the performance of both experimental groups on post-test regarding new grammar, it is concluded that combination recasts are more beneficial in comparison with single-move recasts to make the students aware of their incorrect use of the grammatical points which are taught within their current term. These findings are congruent with previous lines of research conducted by Sheen (2004); Loewen and Philip (2006); Ellis, Loewen and Erlam (2006). Through their research, it was demonstrated that the efficacy of recast is to a large extent related to its saliency. As sheen (2004) puts it, "the extent to which recasts lead to learner uptake and repair may be greater in contexts where the focus of the recasts is more salient". Therefore, in combination recasts the metalinguistic information plays a critical role as the provided information makes the recast completely salient; therefore, recognizable as a corrective feedback for the students.

In contrast to earlier findings of the studies done by Ammar and Spada (2006) and Philip (2003) that highproficiency students can benefit from recasts due to their capability in recognizing them as corrective moves; however, the statistical analyses presented in this study (Tables 2 and 3) do not support this finding, despite of the fact that the participants are upper-intermediate . In fact this inconsistency can be attributed to the novelty of the grammar points, meaning that once the students have been taught a grammatical point since they haven't reached a developmental readiness on the barely learned structures they are unable to "incorporate the target forms addressed in the recasts, into 
their interlanguage" (Ellis, 2006), therefore it can rise to their inability in realizing the recasts. In addition to this, Brown (2000, p.228) identified four stages of what learners experience in terms of errors. The first stage, which is the stage of experimentation and inaccurate guessing, is called random errors. The second stage, called emergent, can be recognized by the students' growth in consistency in linguistic production. The learners have begun to internalize certain rules. This stage is characterized by a crucial factor that students are unable to correct their mistakes when they are pointed by someone else. In fact, this is the level that the learners while learning a new grammar point is experiencing, thereby, Teachers are advised to be fully aware of.

In response to the second research question whether single-move and combination recasts have differing effects in correcting erroneous grammatical patterns stemming from students' previously-learned structures, the data presented in Tables 4 and 5 proved that the participants of both groups enjoyed the benefits of the two corrective moves. Similarly, the provided mean score in Table 7 authenticates this finding. The students' ability in taking the advantage of both combination and single-move recasts can be elucidated by the stage of interlanguage they are experiencing. Brown (2000) maintains "the stage following emergent is called systematic stage in which the learners are able to manifest more consistency in producing the second language. The most critical difference between the emergent and the systematic stages lies in the "ability of learners to correct their errors when they are pointed out - even very subtly- to them". As Brown rightly mentioned once the students have reached a developmental readiness on a particular structure in the systematic stage, even utilizing implicit ways, such as recasts, to notify the students of their deviated utterances will be not only practical, but also effective. An implication of these findings is that teachers should take into account certain elements influencing the efficacy of corrective feedback before deciding on one to resort to, as the results of the present study point out that newness of structure exert influence on the efficacy of non-prompt corrective strategies. Therefore, employing combination recasts can be considered quite effective to correct not only previously-learned structures but also newly-learned ones since they provide the students with metalinguistic information, in fact the reason of correction.

\section{CONCLUSION}

The issue of providing the students with the utmost effective corrective feedback has been a controversial and much disputed subject within the field of second language acquisition. Numerous studies have been designed to enquired into the efficacy of various corrective feedback strategies in English classrooms; in addition, by reviewing the literature an upturn in the number of studies, discovering various influential features in boosting the efficacy of recasts, is discernible. Therefore, in line with previous studies current paper set out with the aim of showing the effect of structure novelty, as a determining factor, on the efficacy of recasts, and the findings highlight the pivotal role of structure novelty on the productiveness of recasts. This effect was substantiated by showing the superiority of combination recasts over singlemove recasts in correcting the fallacious structures emanated from newly-learned structures. And also the equal benefits that both of the above-mentioned corrective feedback have for the students in correcting erroneous utterances which are derived from their previously-learned structures.

\section{REFERENCES}

[1] Allwright, R. L. (1975). Problems in the study of the language teacher's treatment of error. In M. K. Burt \& H. D.Dulay (Eds.), New directions in second language learning, teaching, and bilingual education. Selected papers from the Ninth Annual TESOL Convention. Washington, D.C: TESOL.

[2] Allwright, R. L. \& Bailey, K. M. (1991). Focus on the Language Classroom. New York: Cambridge University Pres

[3] Ammar, A. (2008). Prompts and recasts: Differential effects on second language morphosyntax. Language Teaching Research, $12.2,183-210$.

[4] Ammar, A. \& Spada, N. (2006). One size fits all? Recasts, prompts, and 12 learning. Studies in Second Language Acquisition, 28, 543-74.

[5] Ayoun, D. (2001). The role of negative and positive feedback in the second language acquisition of the passé compose and the imparfait. The Modern Language Journal, 85.2, 226-243.

[6] Braidi, S. (2002). Reexamining the role of recasts in native-speaker/non-native speaker interactions. Language Learning, 52, 142.

[7] Brown, D. H. (2000). Principles of language learning \& teaching. (4th edn.). New York: Longman. (p. 228)

[8] Doughty, C. \& Varela, E. (1998). Communicative focus on form. In C. Doughty \& J.Williams. Focus on form in classroom second language acquisition (pp. 114-138). New York: Cambridge University Press.

[9] Ellis, R. (2009). Corrective feedback and teaching development. L2 Journal, 1.1, 3-18

[10] Ellis, R. \& Loewen, S. \& Erlam, R. (2006). Implicit and explicit corrective feedback and the acquisition of L2 grammar. Studies in Second Language Acquisition, 28, 339-68.

[11] Ellis, R. \& Sheen, Y. (2006). Reexamining the role of recasts in second language acquisition. Studies in Second Language Acquisition, 28, 575-600.

[12] Ellis, R. \& Barkhuizen, G. (2005). Analyzing learner language. Oxford: Oxford University Press.

[13] Han, Z. (2002). A study of the impact of recasts on tense consistency in L2 output. TESOL Quarterly, 36, 543-72.

[14] Havranek, G. (2002). When is corrective feedback most likely to succeed? International Journal of Educational Research, 37.3-4, 255-270. 
[15] Iwashita, N. (2003). Negative feedback and positive evidence in task-based interaction: Differential effects on L2 development. Studies in Second Language Acquisition, 25, 1-36.

[16] Leeman, J. (2003). Recasts and second language development. Studies in Second Language Acquisition, 25, 37-63.

[17] Lightbown, P. \& Spada, N. (2001). Review article: Recasts as feedback to language learners. Language Learning, 51, 719-758.

[18] Lochtman, K. (2002). Oral corrective feedback in the foreign language classroom: how it affects interaction in analytic foreign language teaching. International Journal of Educational Research, 37, 271-83.

[19] Loewen, S. (2005). Incidental focus on form and second language learning. Studies in Second Language Acquisition, 27, 361386.

[20] Loewen, S. \& Philip, J. (2006). Recasts in the adult English L2 classroom: characteristics, explicitness, and effectiveness. The Modern Language Journal, 90, 536-56.

[21] Long, M. H. (1996). The role of the linguistic environment in second language acquisition. In W. Ritchie \& T. Bhatia (Eds.), Handbook of research on second language acquisition (pp. 413-468). New York: Academic.

[22] Lyster, R. (1998). Negotiation of form, recasts, and explicit correction in relation to error types and learner repair in immersion classrooms. Language Learning, 48, 183-218.

[23] Lyster, R. \& Mori, H. (2006). Interactional feedback and instructional counterbalance. Studies in Second Language Acquisition, $28.2,269-300$.

[24] Lyster, R. \& Ranta, L. (1997). Corrective feedback and learner uptake: negotiation of form in communicative classrooms. Studies in Second Language Acquisition, 20, 37-66.

[25] Mackey, A. \& Gass, S. \& McDonough, K. (2000). How do learners perceive interactional feedback? Studies in Second Language Acquisition, 22, 471-497.

[26] Marysia, J. (2004). A philosophy of Second language acquisition. New Haven: Yale University Press.

[27] McDonough, K. (2005). Identifying the impact of negative feedback and learners' responses on ESL question development. Studies in Second Language Acquisition, 27, 79-103.

[28] McDonough, K. \& Mackey, A. (2006). Responses to recasts: Repetitions, primed production, and linguistic development. Language Learning, 56, 693-720.

[29] Mackey, A. \& Philip, J. (1998). Conversational interaction and second language development: recasts, responses, and red herrings? The Modern Language Journal, 82, 338-56.

[30] Nicholas, H. \& Lightbrown, P. M. \& Spada, N. (2001). Recasts as feedback to language learners. Language Learning, 51, 71958.

[31] Nishita, M. (2004). Recasts and repair in the teaching of small group. ASAA E-journal of Asian Linguistics \& Language Teaching, 7, 1-13

[32] Panova, I. \& Lyster, R. (2002). Patterns of corrective feedback and uptake in an adult ESL classroom. TESOL Quarterly, 36, 573-95.

[33] Philip, J. (2003). Constraints on "noticing the gap": Nonnative speakers' noticing of recasts in NS-NNS interaction. Studies in Second Language Acquisition, 25, 99- 126.

[34] Sheen, Y. (2006). Exploring the relationship between characteristics of recasts and learner uptake. Language Teaching Research, 10, 361-92.

[35] Swain, M. (1985). Communicative competence: some roles of comprehensible input and comprehensible output in its development. In S. Gass \& C. Madden (Eds.), Input in second language acquisition (pp. 235-252). Rowley, MA: Newbury House.

[36] Swain, M. (2000). The output hypothesis and beyond: Mediating acquisition through collaborative dialogue. In J.P. Lantolf (Eds.), Sociocultural Theory and Second Language Learning (pp. 97-114). Oxford: Oxford University Press.

[37] Truscott, J. (1999). What's wrong with oral grammar correction? Canadian Modern Language Review, 55,437-456.

[38] Wells, G. (1996). Using the tool-kit of discourse in the activity of learning and teaching. Mind, Culture, and Activity 3.2, 74101.

[39] Wells, G. (2000). Dialogic inquiry in education: Building on Vygotsky's legacy. In J.P. Lantolf (Eds.) Sociocultural Theory and Second Language Learning (pp. 97-114). Oxford: Oxford University Press.

Mohammad Reza Najafi (b. 1984, Shiraz, Iran) holds an MA in TEFL from Bahonar State University, and also a B.A in TEFL from Shiraz Azad University. He is a teacher and a test developer in Navid Language Institute, Shiraz, Iran. He is also an instructor in Dibagaran Language Center. His research interests include corrective feedback and error correction and material development.

Zoobinshid Arshad (b. 1986, Shiraz, Iran) holds an MA in TEFL from Shiraz Azad University. He is a teacher and teacher trainer in Navid English Language Center, Shiraz, Iran. His areas of interests are material development, teacher training and language learning strategies. 